CLINICAL STUDY

\title{
Comparing progression of non-functioning pituitary adenomas in hypopituitarism patients with and without long-term GH replacement therapy
}

\author{
D S Olsson, M Buchfelder ${ }^{1}$, S Schlaffer ${ }^{1}$, B- $\AA$ Bengtsson, K-E Jakobsson ${ }^{2}$, G Johannsson and A G Nilsson \\ Department of Endocrinology, Sahlgrenska University Hospital, SE-413 45 Gothenburg, Sweden, ${ }^{1}$ Department of Neurosurgery, University of \\ Erlangen-Nuremberg, Erlangen, 951054 Germany and ${ }^{2}$ Department of Neurosurgery, Sahlgrenska University Hospital, SE-413 45 Gothenburg, Sweden \\ (Correspondence should be addressed to A G Nilsson; Email: anna.nilsson@medic.gu.se)
}

\begin{abstract}
Objective: An important safety issue with GH replacement therapy (GHRT) in hypopituitary patients with a history of a pituitary adenoma is the risk for tumour recurrence or enlargement.

Design: Case-control study.

Subjects and methods: We studied tumour progression rate in 121 patients with hypopituitarism on the basis of non-functioning pituitary adenomas (NFPA) receiving long-term GHRT. A group of 114 NFPA patients not receiving GHRT who were matched in terms of duration of follow-up, gender, age, age at diagnosis and radiotherapy status were used as a control population. The average duration of GHRT was $10 \pm 4$ years (range $2-17$ ).

Results: In patients with a known residual adenoma, 63\% had no detectable enlargement of tumour during the study. In patients who had no visible residual tumour prior to GHRT, $90 \%$ did not suffer from recurrence. In total, the 10-year tumour progression-free survival rate in patients with NFPA receiving GHRT was 74\%. In the control population not receiving GHRT, the 10-year progression-free survival rate was $70 \%$. Radiotherapy as part of the initial tumour treatment reduced the rate of tumour progression in both GHRT and non-GHRT patients to a similar extent.

Conclusions: The rate of tumour progression was similar in this large group of GHRT patients and the control population not receiving GHRT. Our results provide further support that long-term use of GH replacement in hypopituitarism may be considered safe in patients with residual pituitary adenomas.
\end{abstract}

European Journal of Endocrinology $161663-669$

\section{Introduction}

Pituitary tumours or their treatment are among the main causes of hypopituitarism and severe $\mathrm{GH}$ deficiency (GHD) in adults. The clinical picture of GHD in adults has been recognized since the beginning of the 1990s (1). It has been associated with increased vascular mortality (2-4), premature atherosclerosis (5), abnormal body composition (6), an unfavourable lipid profile (1), reduced muscle strength and fatigue $(1,7)$, and reduced quality of life $(8,9)$. GH replacement therapy (GHRT) has been shown to improve most of these abnormalities (10-13). Long-term GHRT has therefore become common practice in many countries.

There have, however, been some concerns regarding long-term GHRT. A known mitogenic hormone, such as $\mathrm{GH}$, could increase the rate of tumour recurrence or enlargement in patients with a known or unknown residual tumour. Non-functioning pituitary adenoma (NFPA) cells have been shown to express GH receptors in vitro (14). Excess GH, as seen in acromegaly, has been associated with an increased prevalence of premalignant colonic polyps and benign prostatic hyperplasia, but an increased prevalence of cancer has not been demonstrated (15-18). Epidemiological data suggest that increased serum levels of insulin-like growth factor-1 (IGF1) may influence tumour genesis and tumour growth (19). GHRT increases serum IGF1 levels, but the incidence of malignancy during longterm GHRT does not seem to differ from that in the general population (3).

Only a few studies have been published on the longterm effects of GHRT on pituitary adenoma recurrence or enlargement. The limitations of these studies include a low number of enrolled patients, a great diversity of tumour types $(20,21)$, a low frequency of magnetic resonance imaging (MRI) use in follow-up and a relatively short observation time (21-23). Moreover, in previous studies (24), radiotherapy was frequently used and patients so treated were not separated with regard to outcome.

To address the safety issue of whether long-term GHRT is associated with an increased incidence of recurrence or enlargement of pituitary tumours, we 
performed a case-control study involving 121 hypopituitary patients with severe GHD caused by NFPA who had received GHRT over an extended period of time versus closely matched controls involving 114 NFPA patients who had not received GHRT.

\section{Subjects and methods}

\section{Patients}

The study was performed as a case-control study of 394 consecutive adult patients with hypopituitarism and GHD enrolled in an open prospective long-term study of GHRT in adults at the Centre for Endocrinology and Metabolism at the Sahlgrenska University Hospital in Gothenburg, Sweden $(25,26)$. There were three criteria for inclusion in the analysis: i) hypopituitarism caused by a NFPA, ii) GHRT for at least 2 years and iii) imaging performed before commencing GHRT and after at least 2 years of treatment.

A total of 121 patients with NFPA were eligible for inclusion into the study (Table 1). The primary treatment of the tumours included surgical excision in 86 patients, surgical excision combined with radiotherapy in 34 patients and radiotherapy alone in one patient. When surgical excision was undertaken, the approach was in $72 \%$ of the cases transsphenoidal, $25 \%$ transcranial and 3\% unknown. In total, 59\% of NFPA patients had a known residual adenoma upon commencement of GHRT. The percentage of patients for whom radiotherapy was part of the tumour treatment, either as primary treatment (35 patients) or as treatment due to tumour progression (11 patients), was $38 \%$. When radiotherapy was part of the primary treatment, the method used was conventional fractionated radiotherapy.

The average observation period from commencement of GHRT was $10 \pm 4$ years. The patients underwent imaging on a regular basis. At the final imaging, 115 patients $(95 \%)$ were examined with MRI and six

Table 1 Details of enrolled patients, gender distribution, age, age on diagnosis, observation period, proportion of patients primarily treated with surgery and proportion of patients primarily treated with radiotherapy. Values are presented as mean \pm s.D. (range).

\begin{tabular}{lll}
\hline & $\begin{array}{l}\text { NFPA with } \\
\text { GHRT }(n=121)\end{array}$ & $\begin{array}{l}\text { Controls } \\
(n=114)\end{array}$ \\
\hline Gender (M/F) (\%) & $66 / 34$ & $66 / 34$ \\
Age $(\mathrm{yrs})$ & $66.7 \pm 11.2(27-85)$ & $66.7 \pm 11.0(31-87)$ \\
$\begin{array}{c}\text { Age at diagnosis } \\
\text { (yrs) }\end{array}$ & $49.6 \pm 12.8(19-74)$ & $51.6 \pm 12.0(15-75)$ \\
$\begin{array}{c}\text { Observation period } \\
\text { (yrs) }\end{array}$ & $9.9 \pm 3.9(2-17)$ & $10.1 \pm 4.4(2-21)$ \\
$\begin{array}{c}\text { Surgery part of } \\
\text { primary treatment }\end{array}$ & $99 \%$ & $100 \%$ \\
$\begin{array}{c}\text { Radiotherapy part of } \\
\text { primary treatment }\end{array}$ & $29 \%$ & $24 \%$ \\
\hline
\end{tabular}

NFPA, non-functioning pituitary adenoma; GHRT, GH replacement treatment; yrs, years. patients (5\%) with computerized tomography (CT). Panhypopituitarism existed in 81 patients $(67 \%)$, while 17 patients $(14 \%)$ had diabetes insipidus. GHD was diagnosed using conventional criteria $(25,26)$. The $\mathrm{GH}$ dose was titrated individually in order to maintain serum IGF1 levels within the age-related reference range $(27,28)$. The average $\mathrm{GH}$ dose for the enrolled patients was $0.36 \pm 0.13 \mathrm{mg} /$ day (mean \pm s.D.) for men and $0.45 \pm 0.24 \mathrm{mg} /$ day for women. All patients received thyroxine, sex steroids and glucocorticoids as needed.

Informed written consent was obtained from all the patients. The study was approved by the Ethics Committee at the Sahlgrenska University Hospital, Gothenburg, Sweden.

\section{Methods}

The patients were divided into two groups on the basis of tumour status before commencement of GHRT. Patients with a known residual adenoma (59\%) were categorized at the end of the observation period as to the presence or absence of tumour enlargement. Patients without any visible residual adenoma at baseline (41\%) were categorized either as having recurrence or no recurrence at the end of the follow-up (Fig. 1). Tumour recurrence or enlargement was determined through comparison of the imaging appearance of the sella turcica at the end of the observation period compared with the appearance at baseline, before starting GHRT. All tumour recurrence or enlargement, regardless of size or clinical relevance, resulted in categorization as recurrence or enlargement at the time it was first seen on imaging. Recurrence and enlargement were classified as being of clinical significance if any change in clinical management was necessary. Change in clinical management was defined as intervention with surgery or radiotherapy. All imaging was performed as part of a routine clinical surveillance programme, which is individualized, based on age and tumour characteristics, and the period between imaging never exceeds 5 years.

The serum IGF1 concentration was determined by hydrochloric acid ethanol extraction RIA using authentic IGF1 for labelling (Nichols Institute Diagnostics, San Juan Capistrano, CA, USA). The individual serum IGF1 values were compared with age- and sexadjusted values obtained from a reference population of 197 men and 195 women (29). IGF1 SDS were calculated as previously described (30).

\section{Control patients}

To create a control group, the GHRT patients were matched with patients in the hospital database at the Erlangen University Hospital. The matching process involved three mandatory criteria (diagnosis, type of initial treatment and status of $\mathrm{GH}$ substitution) and 


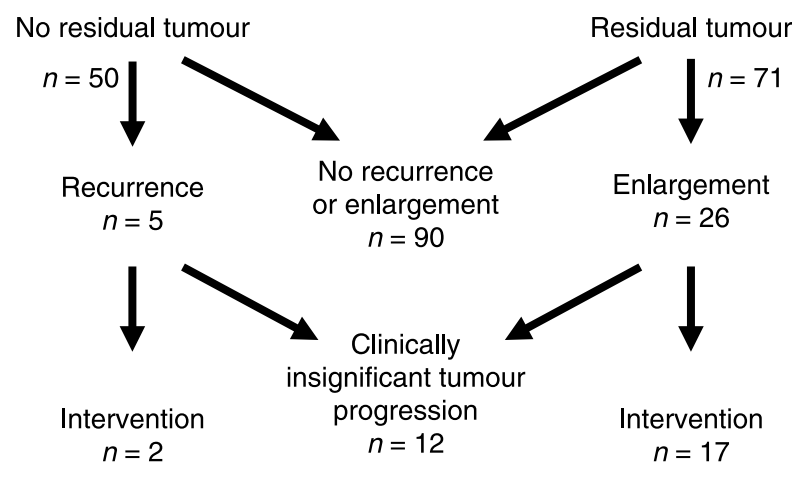

Figure 1 A schematic overview of the classification of the GHRT patients and the numerical outcome. Clinically insignificant tumour progression is defined as tumour growth not resulting in additional tumour treatment. GHRT, GH replacement therapy.

four dispositive criteria (gender, age, age at diagnosis and duration of follow-up). Results of the matching procedure are shown in Table 1. The primary treatment involved surgery alone in 87 patients and surgery combined with radiotherapy in 27 patients. When radiotherapy was part of the primary treatment, the method used was conventional fractionated radiotherapy. The average observation period, i.e. the duration of follow-up from primary tumour treatment, was $10 \pm 4$ years. When surgery was undertaken, as primary treatment, the approach was transsphenoidal in $89 \%$ of patients and transcranial in $11 \%$ of patients. At the end of the follow-up period, $40 \%$ of the patients had received radiotherapy. The status of the tumour was checked regularly, and the last exam was conducted using MRI in 104 patients (91\%) and CT in ten patients (9\%).

The control patients were divided into two groups according to their initial treatment: surgery alone or surgery combined with radiotherapy. On the basis of the imaging reports of the sella turcica, on the last exam, the control patients were subdivided into two groups: progression or no progression.

\section{Statistical methods}

All descriptive statistical analyses are presented as mean value and S.D. Comparisons between different groups of patients were performed using Student's t-test. The level of significance was set at $P<0.05$ with a two-way test. Logistic regression models were used to model the way the dichotomous response variable (recurrence or enlargement) depended on the values of explanatory variables such as gender, age, GHRT duration, age at diagnosis, IGF1 value and the presence of panhypopituitarism.

Kaplan-Meier survival curves and 95\% confidence intervals were obtained for each group to describe the progression-free survival of patients. The log-rank test was used to compare survival times in terms of time to tumour progression.

\section{Results \\ GHRT patients}

Out of the 121 patients treated with $\mathrm{GH}, 90$ patients (74\%) did not develop tumour recurrence or enlargement. One hundred and two patients $(84 \%)$ had no detectable tumour growth or a growth that was deemed clinically insignificant. In all GHRT patients, the 10-year progression-free survival was $74 \%$ (Fig. 2), calculated with Kaplan-Meier regression. The estimated 15-year progression-free survival rate was $67 \%$, but the number of observations available for statistical analysis was small $(n=7)$.

Out of 71 patients who at commencement of GHRT had a detectable residual adenoma, 45 patients $(63 \%)$ did not show evidence of tumour enlargement. In the 26 cases where tumour growth occurred, six patients were treated with surgery, seven patients with radiotherapy, four patients with combined surgery and radiotherapy, while expectation and continued GHRT were considered adequate in nine patients. In total, 54 GHRT patients $(76 \%)$ with a known residual adenoma either had no tumour growth or the enlargement was considered clinically insignificant.

In the group of GHRT patients with no visible residual adenoma at baseline (50 patients), 45 patients $(90 \%)$ did not develop a tumour recurrence during GHRT. Five patients suffered from tumour recurrence, of which two needed surgery, whereas three patients continued without any change in treatment, as the tumour was judged to be clinically insignificant. In total, $96 \%$ of the patients in this group did not

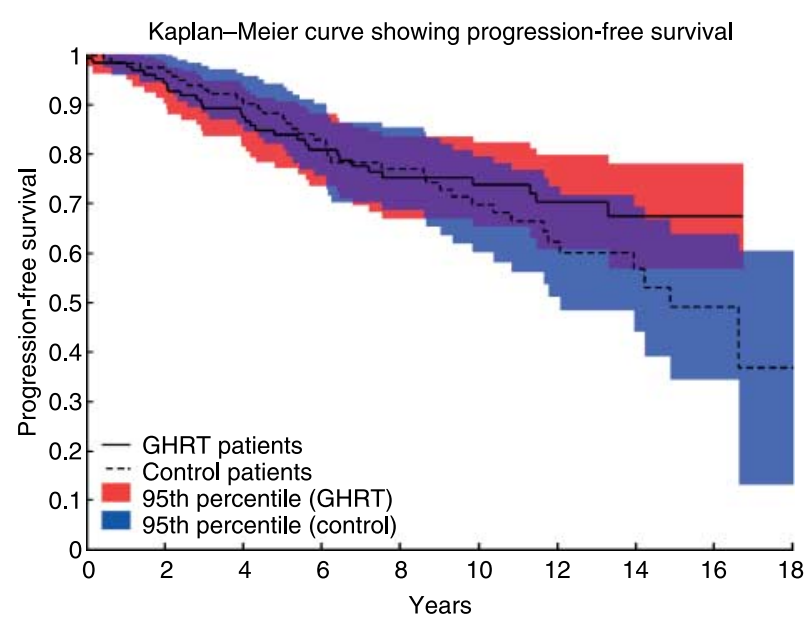

Figure 2 Kaplan-Meier curve of the progression-free survival of patients treated with $\mathrm{GH}$ and patients not treated with $\mathrm{GH}$. The red colour illustrates the 95th percentile of the GHRT group, and the blue colour illustrates the 95th percentile of the control group. No significant difference was found between the groups $(P=0.36)$. GHRT, GH replacement therapy. 
Table 2 Endpoint values for NFPA patients treated with GHRT with or without residual adenoma at baseline and a comparison of subgroups with regard to initial radiotherapy treatment.

\begin{tabular}{llll}
\hline & $\begin{array}{c}\text { Recurrence or } \\
\text { enlargement }\end{array}$ & $\begin{array}{c}\text { No recurrence or } \\
\text { enlargement }\end{array}$ & $\begin{array}{c}\text { No recurrence or enlargement and } \\
\text { clinically insignificant tumour } \\
\text { growth }^{\mathrm{a}}\end{array}$ \\
\hline Residual adenoma $(n=71)$ & $n=26(37 \%)$ & $n=45(63 \%)$ & $n=54(76 \%)$ \\
Without RT $(n=54)$ & $n=24(44 \%)$ & $n=30(56 \%)$ & $n=38(70 \%)$ \\
With RT $(n=17)$ & $n=2(12 \%)$ & $n=15(88 \%)$ & $n=16(94 \%)$ \\
No residual adenoma $(n=50)$ & $n=5(10 \%)$ & $n=45(90 \%)$ & $n=48(96 \%)$ \\
Without RT $(n=32)$ & $n=3(9 \%)$ & $n=29(91 \%)$ & $n=32(100 \%)$ \\
With RT $(n=18)$ & $n=2(11 \%)$ & $n=16(89 \%)$ & $n=16(89 \%)$ \\
\hline
\end{tabular}

NFPA, non-functioning pituitary adenoma; GHRT, GH replacement treatment; RT, radiotherapy.

${ }^{a}$ Clinically insignificant tumour growth is defined as tumour growth not resulting in additional tumour treatment.

have a clinically significant adenoma recurrence (Fig. 1 and Table 2).

There were 35 patients $(29 \%)$ of the total 121 patients, who had received radiotherapy as part of the primary adenoma treatment. In these patients, the estimated 10-year progression-free survival was $88 \%$ compared with $66 \%$ of those with no radiotherapy as part of their initial treatment. In the subgroup who had a residual adenoma at baseline, the percentage of patients that remained stable during long-term GHRT was $88 \%$ for those who had received radiotherapy and $56 \%$ for those who had not received radiotherapy. In patients who had no visible residual adenoma at baseline, a total of $89 \%$ of the patients who had received primary radiotherapy remained without tumour recurrence compared with $91 \%$ of those who had no primary radiotherapy treatment (Fig. 3 and Table 2).

In all patients with GHRT, the mean of the last serum IGF 1 concentration was $206 \pm 93 \mu \mathrm{g} / \mathrm{l}$. There was no significant difference in the serum IGF1 level between patients with tumour recurrence or tumour enlargement $(199 \pm 96 \mu \mathrm{g} / \mathrm{l}$; IGF1 SDS 0.87 \pm 2.0$)$ compared with patients with no recurrence or enlargement of the tumour $(208 \pm 93 \mu \mathrm{g} / \mathrm{l}$; IGF1 SDS $1.0 \pm 1.7)$.

Multivariate analysis considering age, gender, GHRT duration, age at diagnosis, serum IGF1 concentration and the presence of panhypopituitarism did not reveal any association between these variables and tumour progression (data not shown).

\section{Control patients}

Of the 114 patients not receiving GHRT, 77 patients (68\%) did not experience tumour progression. The 10 -year progression-free survival rate was $70 \%$, according to Kaplan-Meier regression. The calculated 15 -year progression-free survival rate was $49 \%$, but the number of observations available for statistical analysis was small $(n=14)$. In the cases where tumour progression occurred, 13 patients were treated with surgery, four patients with radiotherapy, 15 patients with combined surgery and radiotherapy, and in five patients expectation was considered adequate. A total of 82 patients $(72 \%)$ either had no tumour progression or the progression was considered clinically insignificant.

Of the 87 control patients who had not been treated with radiotherapy initially, 50 patients $(57 \%)$ did not develop any tumour progression. The patients in this group had a calculated 10-year progression-free survival rate of $59 \%$. Thirty-seven patients suffered tumour progression, of which 32 needed additional tumour treatment, leaving 55 patients $(63 \%)$ in the non-radiotherapy group with no or clinically insignificant tumour growth. None of the 27 control patients who were given radiotherapy as a primary treatment experienced progression (Table 3 ).

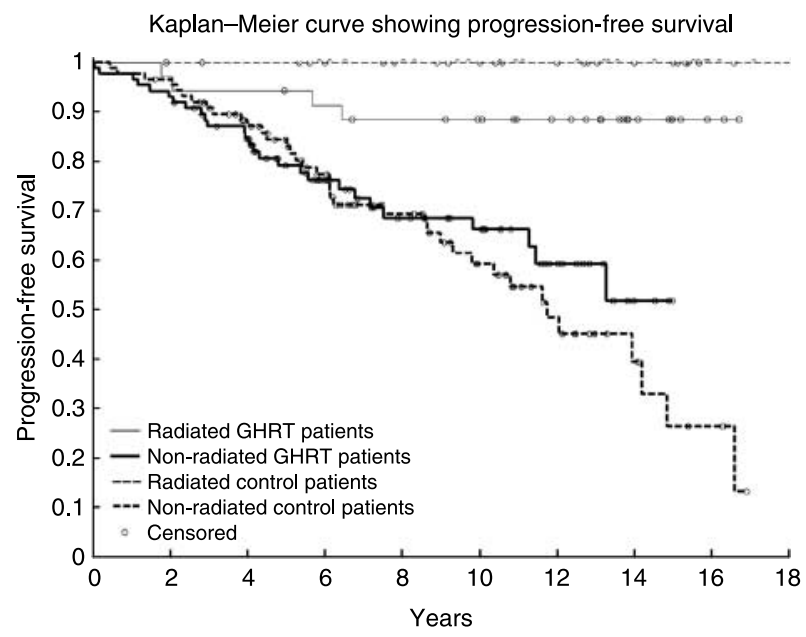

Figure 3 Kaplan-Meier curve of the progression-free survival of four different subgroups: i) GHRT patients primarily treated with radiation, ii) GHRT patients not primarily treated with radiation, iii) control patients primarily treated with radiation and iv) control patients not primarily treated with radiation. The circles indicate censored patients. No significant difference was found between the two subgroups (2 and 4) not primarily treated with radiation $(P=0.45)$. In addition, no significant difference was found between the two subgroups ( 1 and 3 ) initially treated with radiation $(P=0.085)$. GHRT, GH replacement therapy. 
Table 3 Tumour progression in GHRT patients and control patients and a comparison of subgroups with regard to initial radiotherapy treatment.

\begin{tabular}{llll}
\hline & $\begin{array}{c}\text { Tumour } \\
\text { progression }\end{array}$ & $\begin{array}{c}\text { No tumour } \\
\text { progression }\end{array}$ & $\begin{array}{c}\text { No tumour progression and } \\
\text { clinically insignificant tumour } \\
\text { progression }^{\mathrm{a}}\end{array}$ \\
\hline GHRT patients $(n=121)$ & $n=31(26 \%)$ & $n=90(74 \%)$ & $n=102(84 \%)$ \\
Without RT $(n=86)$ & $n=27(31 \%)$ & $n=59(69 \%)$ & $n=70(81 \%)$ \\
With RT $(n=35)$ & $n=4(11 \%)$ & $n=31(89 \%)$ & $n=32(91 \%)$ \\
Control patients $(n=114)$ & $n=37(32 \%)$ & $n=77(68 \%)$ & $n=82(72 \%)$ \\
Without RT $(n=87)$ & $n=37(43 \%)$ & $n=50(57 \%)$ & $n=55(63 \%)$ \\
With RT $(n=27)$ & $n=0(0 \%)$ & $n=27(100 \%)$ & $n=27(100 \%)$ \\
\hline
\end{tabular}

GHRT, GH replacement treatment; RT, radiotherapy.

${ }^{a}$ Clinically insignificant tumour progression is defined as tumour growth not resulting in additional tumour treatment.

\section{Comparison between GHRT patients and control patients}

A comparison between all the GHRT patients and all the control patients found no significant difference in progression-free survival rate $(P=0.36$; Fig. 2$)$.

There was no significant difference between the GHRT and control groups with respect to tumour progressionfree survival rate either in those who had received radiotherapy $(P=0.085)$ or in those who had not $(P=0.45$; Fig. 3$)$.

\section{Discussion}

One concern of long-term GHRT in adults with a history of pituitary tumour has been the risk of an increased rate of tumour recurrence or enlargement. In the present study in patients who had been treated for NFPA and who had a mean duration of GHRT of 10 years, the rate of recurrence or enlargement of NFPA did not differ from patients who had not received GHRT.

There are only a few previous reports on the rate of recurrence or enlargement in patients with NFPA treated with GH. Buchfelder et al. (31) reported a 5-year progression-free survival rate of $71 \%$ in 55 patients (24\% given radiotherapy). Arnold and co-workers (32) reported from 23 patients (none given radiotherapy) a progression-free survival rate of $65 \%$ after a mean period of 6.5 years. In the present study, which is by far the largest, the 10-year progression-free survival rate was $74 \%$ for all 121 GHRT patients and $66 \%$ for the subset of 86 GHRT patients without initial radiotherapy.

The reported 10-year progression-free survival rate in NFPA patients not treated primarily with radiation and not receiving GHRT varies from 56 to $68 \%(33,34)$ in previous publications. In the paper by Arnold et al. (32), of 107 patients with NFPA not receiving radiotherapy and not on GHRT, $64 \%$ had no tumour progression after a mean period of 4.8 years. In comparison, the calculated 10-year progression-free survival rate for the control patients in our study, who had not received GHRT or radiotherapy as primary treatment, was $59 \%$.
Our results in combination with previous reports demonstrate similar tumour progression rates in patients with NFPA with or without GHRT.

In our study, clinically significant recurrence or enlargement of NFPA was not increased in patients receiving long-term GHRT. In view of the growth promoting effects of $\mathrm{GH}$, this is particularly important in patients with a known residual adenoma who receive GHRT. A larger proportion of patients with a residual adenoma developed enlargement of the tumour (37\%) compared with the incidence of recurrence where there was no visible residual adenoma $(10 \%)$. Both in comparison with earlier publications (35) and with the control group in the present study, these figures are comparable with the expected rate of recurrence and enlargement in patients not receiving GHRT. Thus, GHRT can safely be initiated also in all patients with a residual adenoma after initial treatment for a NFPA.

The addition of radiotherapy to the primary surgical treatment is known to increase the 10-year progressionfree rate to $93-97 \%(34,36)$ in patients not receiving GHRT. Also in our GHRT patients, radiotherapy resulted in a higher 10 -year progression-free survival rate ( $88 \mathrm{vs}$ $66 \%$ ). In our control group, none of the patients who had received radiotherapy had a progression. Our measured progression rate for NFPA patients treated with radiotherapy is similar to that reported by Ferrante and coworkers (35). They found no tumour progression after a mean period of 8.1 years in $82 \%$ of patients with NFPA treated with combined surgery and radiotherapy. There is a downside; conventional fractionated radiotherapy has been associated with several complications. Besides the risk of developing additional hormonal deficiencies in patients with partial hypopituitarism $(37,38)$, an increased incidence of optic neuropathy $(37,38)$, cerebrovascular accidents $(39,40)$ and secondary brain tumours $(41)$ has been reported. Minniti et al. (41) in a study of 426 patients with NFPA who received conventional fractionated radiotherapy found the relative risk of a secondary brain tumour to be 10.5 times elevated. Therefore, 
many have abandoned radiotherapy as the primary adjuvant therapy for pituitary adenomas.

When comparing tumour progression rates between different studies, there are some aspects to be taken into consideration. Most studies (such as this one) define tumour progression as even the smallest enlargement on imaging, while others define progression as tumour enlargement requiring treatment. An aspect to the interpretation of our study data is the different definition of baseline in GHRT patients and controls. For GHRT patients, the baseline was set at commencement of GHRT because the time period before GHRT was not part of the study period. In the controls, the baseline was defined as the time of primary tumour treatment. This results in a longer observational period for the GHRT patients than for the control patients, which may overestimate tumour progression in the GHRT patients. On the other hand, at least in theory, some patients may have been excluded from receiving GHRT due to a residual adenoma resulting in an underestimation of tumour progression. We believe that this has not been the case, as the unit in Gothenburg has not used residual adenoma as a contraindication to GHRT.

We believe that a well-conducted randomized trial on the effects of GHRT on pituitary tumour progression is unlikely to be performed. Therefore, the approach used in this study (i.e. a case-control design) might be the best achievable. The strengths of this study are the large number of enrolled patients, the large proportion of patients without radiotherapy, and the long duration of GH treatment and follow-up. Taking into consideration that the growth rate of pituitary tumours is slow, the length of the follow-up period is of utter importance.

In summary, GHRT was not associated with an increased risk of tumour recurrence or tumour enlargement both in comparison with a matched control group and with previous reports in the literature. This study is the first to present results after 10 years of follow-up from a large group of GH-treated NFPA patients and comparing those data with a population receiving a similar standard of care except GHRT. Our results provide further support that the longterm use of GH replacement in hypopituitarism may be considered safe in patients with NFPA, including those with a residual adenoma.

\section{Declaration of interest}

The authors have no financial or other relationships, which might lead to a conflict of interest, besides that $\mathrm{G}$ Johannsson has received unrestricted grants from Novo Nordisk $\mathrm{AB}$ (less than $\$ 10 \mathrm{k}$ ) and Gothenburg University, Sweden (less than \$10k).

\section{Funding}

This work was supported by an unrestricted grant from Novo Nordisk $\mathrm{AB}$ and Gothenburg University, Sweden.

\section{Acknowledgements}

We would like to express our gratitude to the staff at the Centre for Endocrinology and Metabolism at the Department of Endocrinology at Sahlgrenska University Hospital. Special thanks to Nina Vitt at the Department of Neurosurgery, University of Erlangen-Nuremberg for her help with the control group. We would also like to thank Martin Olsson for his help with the statistical analysis.

\section{References}

1 Cuneo RC, Salomon F, McGauley GA \& Sonksen PH. The growth hormone deficiency syndrome in adults. Clinical Endocrinology 199237 387-397.

2 Rosén T \& Bengtsson B-Å. Premature mortality due to cardiovascular disease in hypopituitarism. Lancet 1990336 285-288.

3 Svensson J, Bengtsson B-Å, Rosén T, Odén A \& Johannsson G. Malignant disease and cardiovascular morbidity in hypopituitary adults with or without growth hormone replacement therapy. Journal of Clinical Endocrinology and Metabolism 200489 3306-3312.

4 Bülow B, Hagmar L, Mikocy Z, Nordström CH \& Erfurth EM. Increased cerebrovascular mortality in patients with hypopituitarism. Clinical Endocrinology 199746 75-81.

5 Markussis V, Beshyah SA, Fisher C, Sharp P, Nicolaides AN \& Johnston DG. Detection of premature atherosclerosis by highresolution ultrasonography in symptom-free hypopituitary adults. Lancet $19923401188-1192$.

6 Abs R, Bengtsson B-Å, Hernberg-Stahl E, Monson JP, Tauber JP, Wilton $\mathrm{P} \&$ Wüster $\mathrm{C}$, on behalf of the KIMS Study Group and the KIMS International Board. GH replacement in 1034 growth hormone deficient hypopituitary adults: demographic and clinical characteristics, dosing and safety. Clinical Endocrinology $1999 \mathbf{5 0}$ 703-713.

7 Cuneo RC, Salomon F, Wiles CM \& Sönksen PH. Skeletal muscle performance in adults with growth hormone deficiency. Hormone Research 199033 55-60.

8 Rosén T, Wirén L, Wilhelmsen L, Wiklund I \& Bengtsson B-Å. Decreased psychological well-being in adult patients with growth hormone deficiency. Clinical Endocrinology 199440 111-116.

9 Burman P, Broman JE, Hetta J, Wiklund I, Erfurth EM, Hagg E \& Karlsson FA. Quality of life in adults with growth hormone (GH) deficiency: response to treatment with recombinant human $\mathrm{GH}$ in a placebo-controlled 21 month trial. Journal of Clinical Endocrinology and Metabolism 199580 3585-3590.

10 Russell-Jones DL, Watts GF, Weissberger A, Naoumova R, Myers J, Thompson GR \& Sönksen PH. The effect of growth hormone replacement on serum lipids, lipoproteins, apolipoproteins and cholesterol precursors in adult growth hormone deficient patients. Clinical Endocrinology $1994 \mathbf{4 1}$ 345-350.

11 Bengtsson B-Å, Koppeschaar HP, Abs R, Bennmarker H, Hernberg-Stahl E, Westberg B, Wilton P, Monson JP, FeldtRasmussen U \& Wüster C, on behalf of the KIMS Study Group. Growth hormone replacement therapy is not associated with any increase in mortality. Journal of Clinical Endocrinology and Metabolism 199984 4291-4292.

12 Nass R, Huber RM, Klauss V, Müller OA, Schopohl J \& Strasburger CJ. Effect of growth hormone (hGH) replacement therapy on physical work capacity and cardiac and pulmonary function in patients with hGH deficiency acquired in adulthood. Journal of Clinical Endocrinology and Metabolism $1995 \mathbf{8 0}$ 552-557.

13 Carroll PV, Christ ER, Bengtsson B-Å, Carlsson L, Christiansen JS, Clemmons D, Hintz R, Ho K, Laron Z, Sizonenko P, Sönksen PH, Tanaka T \& Thorner M. Growth hormone deficiency in adulthood and the effects of growth hormone replacement: a review. Journal of Clinical Endocrinology and Metabolism $1998 \mathbf{8 3}$ 382-395. 
14 Clausen LR, Kristiansen MT, Rasmussen LM, Billestrup N, Blaabjerg O, Ledet $\mathrm{T}$ \& Jørgensen JOL. Growth hormone receptor expression and function in pituitary adenomas. Clinical Endocrinology $200460576-583$.

15 Monson JP. Growth hormone (GH) replacement therapy: cancer in adults treated with GH. Growth Hormone and IGF Research 2000 10 S50-S51.

16 Jenkins PJ, Fairclough PD, Richards T, Lowe DG, Monson J, Grossman A, Wass JAH \& Besser M. Acromegaly, colonic polyps and carcinoma. Clinical Endocrinology 199747 17-22.

17 Sonksen P, Jacobs H, Orme S \& Belchetz P. Acromegaly and colonic cancer. Clinical Endocrinology 199747 647-648.

18 Colao A, Marzullo P, Spiezia S, Ferone D, Giaccio A, Cerbone G, Pivonello R, Di Somma C \& Lombardi G. Effect of growth hormone $(\mathrm{GH})$ and insulin-like growth factor-I on prostate diseases: an ultrasonographic and endocrine study in acromegaly, GH deficiency and healthy subjects. Journal of Clinical Endocrinology and Metabolism 199984 1986-1991.

19 Renehan AG, Zwahlen M, Minder C, O’Dwyer ST, Shalet SM \& Egger M. Insulin-like growth factor (IGF)-1, IGF binding protein -3, and cancer risk: systematic review and met-regression analysis. Lancet 2004363 1346-1353.

20 Chung TT, Evanson J, Walker D, Akker SA, Besser GM, Monson JP, Grossman $\mathrm{AB} \&$ Drake WM. Safety of growth hormone replacement in hypopituitary patients with non-irradiated pituitary and peri-pituitary tumours. Clinical Endocrinology 2008 68 965-969.

21 Hatrick AG, Boghalo P, Bingham JB, Ayres AB, Sonksen PH \& Russell-Jones DL. Does GH replacement therapy in adult $\mathrm{GH}$-deficient patients result in recurrence or increase in size of pituitary tumours? European Journal of Endocrinology 2002146 807-811.

22 Frajese G, Drake WM, Loureiro RA, Evanson J, Coyte D, Wood DF, Grossman AB, Besser GM \& Monson JP. Hypothalamo-pituitary surveillance imaging in hypopituitary patients receiving longterm GH replacement therapy. Journal of Clinical Endocrinology and Metabolism $2001865172-5175$.

23 Minniti G, Traish D, Ashley S, Gonsalves A \& Brada M. Fractionated stereotactic conformal radiotherapy for secreting and nonsecreting pituitary adenomas. Clinical Endocrinology 2006 $64542-548$

24 Chung TT, Drake WM, Evanson J, Walker D, Plowman PN, Chew SL, Grossman AB, Besser GM \& Monson JP. Tumour surveillance imaging in patients with extrapituitary tumours receiving growth hormone replacement. Clinical Endocrinology $200563274-279$.

25 Gotherstrom G, Svensson J, Koranyi J, Alpsten M, Bosæus I, Bengtsson B-Å \& Johannsson G. A prospective study of 5 years of $\mathrm{GH}$ replacement therapy in GH-deficient adults: sustained effects on body composition, bone mass, and metabolic indices. Journal of Clinical Endocrinology and Metabolism 200186 4657-4665.

26 Gotherstrom G, Bengtsson B- $\AA$, Bosæeus I, Johannsson G \& Svensson J. A ten-year, prospective study of the metabolic effects of growth hormone replacement in adults. Journal of Clinical Endocrinology and Metabolism 200792 1442-1445.

27 Johannsson G, Rosén T \& Bengtsson B-Å. Individualized dose titration of growth hormone $(\mathrm{GH})$ during $\mathrm{GH}$ replacement in hypopituitary adults. Clinical Endocrinology 1997 47 571-581.

28 Drake WM, Coyte D, Camacho-Hübner C, Jivanji NM, Kaltsas G, Wood DF, Trainer PJ, Grossman AB, Besser GM \& Monson JP. Optimising growth hormone replacement therapy by dose titration in hypopituitary adults. Journal of Clinical Endocrinology and Metabolism $1998 \mathbf{8 3} 3913-3919$.
29 Landin-Wilhelmsen K, Wilhelmsen L, Lappas G, Rosén T, Lindstedt G, Lundberg P-A \& Bengtsson B-A. Serum insulin-like growth factor $I$ in a random population sample of men and women: relation to age, sex, smoking habits, coffee consumption and physical activity, blood pressure and concentrations of plasma lipids, fibrinogen, parathyroid hormone and osteocalcin. Clinical Endocrinology $1994 \mathbf{4 1} 351-357$.

30 Svensson J, Johannsson G \& Bengtsson B-A․ Insulin-like growth factor-I in growth hormone-deficient adults: relationship tp population-based normal values, body composition and insulin tolerance test. Clinical Endocrinology $1997 \mathbf{4 6} 579-586$.

31 Buchfelder M, Kann PH, Wüster C, Tuschy U, Saller B, Brabant G, Kleindienst A \& Nomikos P, the German KIMS Board. Influence of GH substitution therapy in deficient adults on the recurrence rate of hormonally inactive pituitary adenomas: a case-control study. European Journal of Endocrinology 2007157 149-156.

32 Arnold JR, Arnold DF, Marland A, Karavitaki N \& Wass JAH. Growth hormone replacement in patients with non-functioning pituitary adenoma treated solely by surgery is not associated with increased risk of tumour recurrence. Clinical Endocrinology 2009 70 435-438.

33 Turner HE, Stratton IM, Byrne JV, Adams CBT \& Wass JAH. Audit of selected patients with non-functioning pituitary adenomas treated without irradiation - a follow-up study. Clinical Endocrinology 199951 281-284.

34 Gittoes NJL, Bates AS, Tse W, Bullivant B, Sheppard MC, Clayton RN \& Stewart PM. Radiotherapy for non-functioning pituitary tumours. Clinical Endocrinology $1998 \mathbf{4 8} 331-337$.

35 Ferrante E, Ferraroni M, Castrignanò T, Menicatti L, Anagni M, Reimondo G, Del Monte P, Bernasconi D, Loli P, Faustini-Fustini M, Borretta G, Terzolo M, Losa M, Morabito A, Spada A, BeckPeccoz P \& Lania AG. Non-functioning pituitary adenoma database: a useful resource to improve the clinical management of pituitary tumors. European Journal of Endocrinology $2006 \mathbf{1 5 5}$ 823-829.

36 Brada M, Rajan B, Traish D, Ashley S, Holmes-Sellors PJ, Nussey S $\&$ Uttley D. The long-term efficacy of conservative surgery and radiotherapy in the control of pituitary adenomas. Clinical Endocrinology 199338 571-578.

37 Minniti G, Jaffrain-Rea ML, Osti M, Cantore G \& Enrici RM. Radiotherapy for nonfunctioning pituitary adenomas: from conventional to modern stereotactic radiation techniques. Neurosurgical Review 200730 167-176.

38 Boelaert K \& Gittoes NJL. Radiotherapy for non-functioning pituitary adenomas. European Journal of Endocrinology $2001 \mathbf{1 4 4}$ 569-575.

39 Brada M, Ashley S, Ford D, Traish D, Burchell L \& Rajan B. Cerebrovascular mortality in patients with pituitary adenoma. Clinical Endocrinology 200257 713-717.

40 Erfurth EM, Bülow B, Svahn-Tapper G, Norrving B, Odh K, Mikoczy Z, Bjork J \& Hagmar L. Risk factors for cerebrovascular deaths in patients operated and irradiated for pituitary tumors. Journal of Clinical Endocrinology and Metabolism $2002 \quad \mathbf{8 7}$ 4892-4899.

41 Minniti G, Traish D, Ashley S, Gonsalves A \& Brada M. Risk of second brain tumour after conservative surgery and radiotherapy for pituitary adenoma: update after an additional 10 years. Journal of Clinical Endocrinology and Metabolism 20059 800-804.

Received 2 September 2009

Accepted 3 September 2009 